\title{
A SUSTENTABILIDADE EMPRESARIAL NA PRESCRIÇÃO DAS EXECUÇÕES FISCAIS COMO MODELO COOPERATIVO PROCESSUAL
}

\author{
THE CORPORATE SUSTAINABILITY TAX EXECUTIONS' \\ PRESCRIPTION LIKE THE PROCEDURAL COOPERATIVE MODEL
}

\author{
José Laurindo de Souza Netto ${ }^{1}$ \\ Adriane Garcel ${ }^{2}$ \\ Gustavo Calixto Guilherme ${ }^{3}$
}

\begin{abstract}
RESUMO
O presente artigo objetiva contextualizar o modelo cooperativo do Código de Processo Civil nas execuções fiscais para o reconhecimento da prescrição tributária. Trata-se de uma análise doutrinária e jurisprudencial que apresenta a nova perspectiva do Código, as características da prescrição tributária e os julgados recentes dos Tribunais. $\mathrm{O}$ artigo conclui que a aplicação do modelo cooperativo processual permite a verificação da prescrição tributária nas execuções fiscais, em primazia com os princípios da razoável duração do processo e da segurança jurídica.
\end{abstract}

Palavras-chave: Prescrição Tributária; Execuções Fiscais; Modelo Processual Cooperativo; Sustentabilidade Empresarial.

\section{ABSTRACT}

\footnotetext{
${ }^{1}$ Pós-doutor pela Faculdade de Direito da Universidade Degli Studi di Roma - La Sapienza. Estágio de Pósdoutorado em Portugal. Professor permanente no Mestrado da Universidade Parananense - UNIPAR. Desembargador do Tribunal de Justiça do Paraná, $2^{\circ}$ Vice-Presidente, membro de seu Órgão especial e Presidente do NUPEMEC.

${ }^{2}$ Mestranda em Direito Empresarial e Cidadania no Centro Universitário de Curitiba - UNICURITIBA. Pesquisadora no grupo de pesquisa: Crise da Jurisdição e mercado: efetividade e plenitude institucional; Direito Penal Econômico: repercussões interdisciplinares na política-criminal econômica e impactos nas categorias dogmáticas do delito e da pena; Compliance - Registrados no CNPq. Mediadora Judicial. Assessora Jurídica no Tribunal de Justiça do Estado do Paraná.

${ }^{3}$ Especialista em direito processual civil pelo Centro de Estudos Jurídicos Prof. Luiz Carlos. Graduado em Direito pela Universidade Positivo e em Administração pela Universidade Federal do Paraná - UFPR. Assessor JurídicoAdministrativo do Núcleo de Inteligência da $2^{\text {a }}$ Vice-Presidência do Tribunal de Justiça do Estado do Paraná.
} 
This article aims to contextualize the Civil Procedure Code's cooperative model in tax executions for the recognition of tax prescription. It is a doctrinal and jurisprudential analysis that presents the new perspective of the Civil Procedure Code, the characteristics of tax prescription and the recents judgments of the Courts. The article concludes that the application of the cooperative procedural model allows the verification of prescription in tax executions, in primacy with the principles of the reasonable length of process and the legal certainty.

Keywords: Tax prescription; Tax executions; Cooperative process model; Corporate sustainability.

\section{INTRODUÇÃO}

A prescrição tributária é um tema de grande relevância no ordenamento jurídico, diante da enorme quantidade de execuções fiscais ajuizadas pela Fazenda Pública.

Constituído de maneira definitiva o crédito tributário, inicia-se o prazo prescricional para que o ente público possa satisfazer a sua pretensão, por meio do ajuizamento da ação e da busca pela citação e por bens do executado.

Devido às diversas características que envolvem o referido instituto e à subjetividade da Súmula 106 do Superior Tribunal de Justiça, deverá ser levada em consideração a atuação dos sujeitos processuais no histórico de cada processo para que seja decretada a prescrição do crédito tributário.

Com o advento do Código de Processo Civil, estabeleceu-se um novo modelo de estruturação processual, o de cooperação entre os sujeitos processuais. Dessa forma, o magistrado e as partes deverão interagir entre si visando uma decisão justa e efetiva em tempo razoável a fim de primar pelos princípios do processo civil constitucional, como o devido processo legal, a razoável duração do processo e a segurança jurídica.

O presente estudo visa aplicar as novas diretrizes processuais em âmbito tributário com o intuito de possibilitar o reconhecimento da prescrição em execuções fiscais.

Primeiramente o presente artigo irá abordar os modelos clássicos de estruturação processuais e o novo modelo cooperativo do Código de Processo Civil.

Em um segundo momento, apresentar-se-á o conceito e as características da prescrição tributária, bem como a Súmula 106 do Superior Tribunal de Justiça.

Por fim, será demonstrado de que modo tem se posicionado a jurisprudência do Tribunal de Justiça do Estado do Paraná, visando responder, através do modelo processual cooperativo, quando é possível a ocorrência da prescrição tributária em executivos fiscais. 


\section{A PERSPECTIVA COOPERATIVA DO PROCESSO CIVIL E OS MODELOS DE ESTRUTURAÇÃO PROCESSUAIS}

No Estado Constitucional, a relação jurídica processual está atrelada aos direitos fundamentais e aos princípios estabelecidos na Constituição Federal. O processo não pode mais ser visto somente no seu aspecto interno, mas sim em uma dimensão externa, buscando produzir decisões legítimas e justas capazes de formar precedentes, orientando o Poder Judiciário e a sociedade civil como um todo (ARENHART; MARINONI; MITIDIERO, 2017, p. 491-492).

Assim, o objeto do processo civil, anteriormente centrado na concepção clássica de composição e regulação do conflito entre as partes, passou a pautar-se na garantia dos direitos fundamentais processuais e materiais previstos pelo ordenamento jurídico (ARAÚJO, 2016, p. 65).

Essa nova perspectiva fica evidente com o advento do Novo Código de Processo Civil, que incluiu no ordenamento jurídico um terceiro modelo de organização processual. Além do sistema misto dos modelos tradicionais de estruturação de processo, dispositivo e inquisitivo (THEODORO JÚNIOR, 2012, p. 35), surge o modelo cooperativo, baseado nos princípios do devido processo legal, da boa-fé processual, do contraditório (DIDIER JR, 2017, p. 141) e da razoável duração do processo.

\section{$1.1 \mathrm{O}$ ARTIGO $2^{\circ}$ DO CÓDIGO DE PROCESSO CIVIL E OS PRINCÍPIOS DISPOSITIVO E DO IMPULSO OFICIAL.}

O Código de Processo Civil de 2015, consagra em seu artigo $2^{\circ}$ os princípios dispositivo e do impulso oficial (NEVES, 2017, p. 183), inseridos entre as normas fundamentais do Direito Processual Civil (Capítulo I), segundo o qual "o processo começa por iniciativa da parte e se desenvolve por impulso oficial, salvo as exceções previstas em lei”.

Da leitura do referido artigo vislumbra-se inicialmente um protagonismo da parte ao provocar a jurisdição, visando tutelar seus direitos mediante o ajuizamento da ação, que se transfere ao magistrado, o qual, através do princípio do impulso oficial, torna-se responsável

\footnotetext{
${ }^{4}$ Art. $2^{\circ}$. O processo começa por iniciativa da parte e se desenvolve por impulso oficial, salvo as exceções previstas em lei. (BRASIL, 2015)
} 
pela condução do processo. A divisão supracitada nada mais é do que a concretização dos dois modelos clássicos de estruturação do processo, o adversarial e o inquisitorial (DIDIER JR, 2017, p. 137).

No modelo adversarial prepondera o princípio dispositivo, no qual o processo desenvolve-se entre adversários diante de um órgão jurisdicional relativamente passivo. Já o modelo inquisitorial revela-se focado na figura do magistrado, com suas atribuições no sentido de conduzir e instruir o processo (DIDIER JR, 2017, p. 136-137).

Humberto Theodoro Júnior esclarece tal distinção, em seu livro Curso de Direito Processual Civil:

\footnotetext{
Caracteriza-se o princípio inquisitivo pela liberdade da iniciativa conferida ao juiz, tanto na instauração da relação processual como no seu desenvolvimento. Por todos os meios a seu alcance, o julgador procura descobrir a verdade real, independentemente de iniciativa ou a colaboração das partes. Já o princípio dispositivo atribui às partes toda a iniciativa, seja na instauração do processo, seja no seu impulso. As provas só podem, portanto, ser produzidas pelas próprias partes, limitando-se o juiz à função de mero espectador. (THEODORO JÚNIOR, 2012, p. $35)$.
}

O caráter dispositivo ou inquisitivo pode manifestar-se em relação a vários temas do andamento processual, como na instauração do processo, produção de provas e recursos, podendo o legislador, em um tema, atribuir enfoque maior às partes e em outro, ao magistrado (DIDIER JR, 2017, p. 138).

Feitas as considerações iniciais, impende destacar que o artigo $2^{\circ}$ do novo Código (artigo 262 do CPC/73), atribuiu um caráter inquisitivo ao impulso processual (NEVES, 2017, p. 183), sendo o andamento e sua condução funções do Estado-juiz (MARINONI; MITIDIERO, 2014, p. 252).

Apesar de o impulso da ação ser oficial, o fundamento do processo civil constitucional exige que ele seja dialético (MARINONI; MITIDIERO, 2013, p. 707), envolvendo todos os sujeitos processuais. Nesse sentido, o desenvolvimento do processo só é possível através de atos das partes, correspondendo a um ônus processual para os litigantes (WAMBIER; ALMEIDA; TALAMINI, 2005, p. 180).

No diálogo entre partes e juiz, é fundamental a cooperação entre todos os envolvidos, para que o processo seja célere e alcance o resultado final da maneira mais adequada, de preferência com uma sentença de mérito: 
Afinal, é de interesse público que o processo não fique parado, que seja ágil e que chegue logo ao fim, que, como se verá, deve ser preferencialmente uma sentença de mérito (...). (WAMBIER; CONCEIÇÃO; RIBEIRO; MELLO, 2015, p. 57).

Assim é a perspectiva do novo Código, pautado no princípio da cooperação entre os sujeitos processuais.

\title{
1.2 O NOVO MODELO PROCESSUAL COOPERATIVO.
}

O novo Código de Processo Civil consagrou de forma expressa o princípio da cooperação em seu artigo $6^{\circ}$, estabelecendo que todos os sujeitos processuais devem cooperar visando uma decisão de mérito justa e efetiva em tempo razoável.

Esse novo modelo de processo é caracterizado pelo redirecionamento do princípio do contraditório com a inserção do órgão jurisdicional no rol dos sujeitos do diálogo processual (DIDIER JR, 2017, p. 141), envolvendo a colaboração das partes com o juiz, do juiz com as partes e das partes entre si (NEVES, 2017, p. 205).

A colaboração visa organizar o papel do magistrado e das partes na conformação do processo, estruturando-o como uma verdadeira comunidade de trabalho (MARINONI; MITIDIERO, 2013, p. 708).

Desse modo, no andamento processual, deve ser levada em consideração a perspectiva do processo civil constitucional, baseado na cooperação entre os sujeitos processuais de modo a obter uma decisão justa aos envolvidos.

Nas palavras de José Laurindo de Souza Netto:

\begin{abstract}
A natureza principiológica da cooperação obriga os sujeitos processuais a pautarem as respectivas condutas, seja na iniciativa, seja no desenvolvimento do processo, em deveres de lealdade, eticidade e colaboração para o alcance de um resultado decisório que seja obra em coautoria. (SOUZA NETTO, 2016, p. 417).
\end{abstract}

Fazendo um paralelo com o Direito Tributário, espera-se, nesse enfoque, a atuação efetiva do magistrado na condução dos atos processuais e da Fazenda Pública visando à satisfação de seu crédito, garantindo-se o interesse público.

\section{CARACTERÍSTICAS RELEVANTES DA PRESCRIÇÃO TRIBUTÁRIA PARA A APLICAÇÃo dO MODELO COOPERATIVO DE PROCESSO}

\footnotetext{
${ }^{5}$ Art. $6^{\circ}$. Todos os sujeitos do processo devem cooperar entre si para que se obtenha, em tempo razoável, decisão de mérito justa e efetiva (BRASIL,2015).
} 


\subsection{O INSTITUTO DA PRESCRIÇÃO}

O instituto da prescrição foi conceituado por Clóvis Beviláqua como "a perda da ação atribuída a um direito, e de toda a sua capacidade defensiva, em consequência do não uso delas, durante um determinado espaço de tempo" (1953, p. 370, apud PELUSO, 2013, p. 140).

Trata-se de um mecanismo jurídico que fulmina a aptidão para exigir o cumprimento de um direito na via judicial, pelo decurso do prazo previsto em lei. (DONIZETTI; QUINTELLA, 2017, p. 2017).

Alguns autores a justificam como uma sanção à negligência do titular do direito que não o exerce em determinado período de tempo, enquanto outros procuram explicá-la com motivos de ordem pública, dada a necessidade de estabilizar as situações jurídicas (PELUSO, 2013, p. 140).

Na seara tributária não é diferente. A prescrição está prevista no artigo 174 do Código Tributário Nacional, sendo que a Fazenda Pública tem o prazo de cinco anos para exercer o seu direito de ação, propondo a execução fiscal.

$\mathrm{O}$ artigo $156^{6}$, inciso $\mathrm{V}$, do Código Tributário Nacional, dispõe ainda que a prescrição não atinge somente o direito de ação para a cobrança do tributo inadimplido, mas também extingue o próprio crédito tributário.

Nas palavras do Ministro do Superior Tribunal de Justiça Luiz Fux, quando do julgamento do Recurso Especial Repetitivo no 1102431/RJ (BRASIL, 2009):

\footnotetext{
O conflito caracterizador da lide deve estabilizar-se após o decurso de determinado tempo sem promoção da parte interessada pela via da prescrição, impondo segurança jurídica aos litigantes, uma vez que a prescrição indefinida afronta os princípios informadores do sistema tributário.
}

Feitas as considerações iniciais, doutrina e jurisprudência estabelecem duas espécies de prescrição tributária: a de direito material ou direta e a intercorrente.

2.2 A prescrição de direito material ou direta.

\footnotetext{
${ }^{6}$ Art. 156. Extinguem o crédito tributário: (...) V - a prescrição e a decadência;
} 
A prescrição de direito material ou direta está prevista no caput do artigo 174 do Código Tributário Nacional, o qual dispõe que "a ação para a cobrança do crédito tributário prescreve em cinco anos, contados da data da sua constituição definitiva".

O parágrafo único do referido $\operatorname{artigo~}^{7}$ estabelece as hipóteses de interrupção da prescrição, em seus incisos I a IV, assim dispostas: o despacho citatório em execução fiscal, o protesto judicial, qualquer ato judicial que constitua em mora o devedor e qualquer ato inequívoco ainda que extrajudicial, que importe em reconhecimento do débito pelo devedor.

O inciso I do dispositivo supracitado merece especial relevo, na medida em que abrange a maioria das ações referentes à prescrição tributária de competência recursal das Câmaras Cíveis do Tribunal de Justiça do Estado do Paraná.

Nessa esteira, é necessário esclarecer que a Lei Complementar ${ }^{\circ} 118 / 2005$ alterou o entendimento do inciso mencionado, sendo que, anteriormente à sua promulgação, a interrupção da prescrição se dava pela efetiva citação do devedor e não pelo despacho judicial, como ocorre atualmente.

Mister salientar ainda que, para verificar a aplicação da redação atual ou originária do artigo supracitado, deve-se levar em conta a data do despacho judicial citatório da execução fiscal, conforme decidido no RESP. 999.901/RS (BRASIL,2009) sob pena de retroação da legislação processual.

Desse modo, para que se caracterize a ocorrência da prescrição de direito material, faz-se necessário que tenham transcorridos cinco anos da constituição definitiva do crédito tributário até a citação do devedor (se o despacho citatório foi exarado anteriormente à Lei Complementar 118/2005) ou até o próprio despacho de citação (caso o despacho tenha ocorrido após o advento da LC 118/2005, em 09.06.2005).

A expressão constituição definitiva do crédito tributário não é de fácil interpretação, como bem mencionado pelo autor Eduardo Sabbag, em seu livro Manual de Direito Tributário. O conceito está atrelado a ideia de "definitividade" do crédito, decorrente do momento em que não seja mais possível ao Fisco discutir administrativamente a seu respeito (SABBAG, 2013, p. 819).

Como regra geral, entende-se como constituição definitiva do crédito tributário a data da notificação do contribuinte, conforme entendimento do RESP 1320825/RJ

\footnotetext{
${ }^{7}$ Art. 174. A ação para a cobrança do crédito tributário prescreve em cinco anos, contados da data da sua constituição definitiva. Parágrafo único. A prescrição se interrompe: I - pelo despacho do juiz que ordenar a citação em execução fiscal; (Redação dada pela Lcp no 118 , de 2005) II - pelo protesto judicial; III - por qualquer ato judicial que constitua em mora o devedor; IV - por qualquer ato inequívoco ainda que extrajudicial, que importe em reconhecimento do débito pelo devedor.
} 
(BRASIL,2016), julgado submetido, inclusive, ao rito dos recursos repetitivos. Importante se faz o destaque de parte do acórdão, para uma melhor elucidação do tema:

Reconhecida a regular constituição do crédito tributário, não há mais que falar em prazo decadencial, mas sim em prescricional, cuja contagem deve se iniciar no dia seguinte à data do vencimento para o pagamento da exação, porquanto antes desse momento o crédito não é exigível do contribuinte. (BRASIL, 2016)

Acerca do assunto, oportuno o magistério de Eduardo Sabbag:

Resumidamente, o termo a quo da contagem do prazo quinquenal de prescrição será: a) a data da notificação do lançamento (mais 30 dias) $^{8}$, caso não se verifique a protocolização de impugnação administrativa do lançamento; b) a data da notificação da decisão administrativa final, mantendo total ou parcialmente o tributo exigido. (SABBAG, 2013, p. 820).

Dessa forma, considera-se, na maioria dos casos, a data seguinte ao dia do vencimento do tributo como início do prazo prescricional, visto ser posterior à constituição do crédito e após findada a possibilidade de impugnação administrativa pelo sujeito passivo da obrigação tributária.

Por oportuno, registre-se que, na eventual hipótese de inexistir o marco anterior, a jurisprudência do Tribunal de Justiça do Estado do Paraná ${ }^{9}$ tem considerado o dia posterior à inscrição do débito em dívida ativa como o termo inicial da contagem do lustro prescricional. Isso porque a inscrição em dívida ativa é considerada ato administrativo que tem como pressuposto o vencimento do tributo, consoante o artigo $201^{10}$ do Código Tributário Nacional.

Durante o quinquênio prescricional material, a Fazenda Pública deve ser diligente no sentido de ajuizar tempestivamente a execução fiscal, encontrar o endereço do devedor e requerer a citação do executado pelas mais diversas modalidades, sob pena de ser declarada a prescrição material pelo transcurso do quinquênio entre a constituição do crédito tributário e a citação do devedor ou o despacho citatório.

\subsection{A PRESCRIÇÃO INTERCORRENTE.}

\footnotetext{
${ }^{8}$ Art. 15 do Decreto n. 70.235/72 (Processo Administrativo Fiscal): Art. 15. A impugnação, formalizada por escrito e instruída com os documentos em que se fundamentar, será apresentada ao órgão preparador no prazo de trinta dias, contados da data em que for feita a intimação da exigência.

${ }^{9}$ TJ/PR - AC 1712713-8, $2^{a}$ C. Cível, Rel. Des. Silvio Dias, 03.10.2017. TJ/PR - AC 1726347-3, 2 ${ }^{a}$ C. Cível, Rel. Des. Antônio Renato Strapasson, 31.10.2017.

${ }^{10}$ Art. 201. Constitui dívida ativa tributária a proveniente de crédito dessa natureza, regularmente inscrita na repartição administrativa competente, depois de esgotado o prazo fixado, para pagamento, pela lei ou por decisão final proferida em processo regular (BRASIL, 1966)
} 
Após a interrupção da prescrição de direito material, seja pela citação do devedor (despacho citatório anterior à LC 118/2005), seja pelo próprio despacho de citação (despacho posterior à LC 118/2005), inicia-se no curso dos executivos fiscais a análise da prescrição intercorrente.

A prescrição intercorrente ocorre no andamento das execuções fiscais quando, não sendo encontrados o devedor ou bens penhoráveis, há desídia da Fazenda Pública na movimentação processual por prazo superior a cinco anos (HABLE, 2014, p. 152-153).

O referido instituto possui trâmite específico, inserido expressamente no Direito Tributário com o advento da Lei $n^{\circ} 11.051 / 2004$, ao incluir o $\$ 4^{\circ}$ no artigo 40 da Lei $n^{\circ}$ 6.830/1980 (Lei de Execução Fiscal), que assim disciplina:

\footnotetext{
Art. 40 - O Juiz suspenderá o curso da execução, enquanto não for localizado o devedor ou encontrados bens sobre os quais possa recair a penhora, e, nesses casos, não correrá o prazo de prescrição.

$\S 1^{\circ}$ - Suspenso o curso da execução, será aberta vista dos autos ao representante judicial da Fazenda Pública.

$\S 2^{\circ}$ - Decorrido o prazo máximo de 1 (um) ano, sem que seja localizado o devedor ou encontrados bens penhoráveis, o Juiz ordenará o arquivamento dos autos.

$\S 3^{\circ}$ - Encontrados que sejam, a qualquer tempo, o devedor ou os bens, serão desarquivados os autos para prosseguimento da execução.

$\S 4^{\circ}$ - Se da decisão que ordenar o arquivamento tiver decorrido o prazo prescricional, o juiz, depois de ouvida a Fazenda Pública, poderá, de ofício, reconhecer a prescrição intercorrente e decretá-la de imediato. (Incluído pela Lei $\mathrm{n}^{\circ}$ 11.051, de 2004)

$\S 5^{\circ}$ - A manifestação prévia da Fazenda Pública prevista no $§ 40$ deste artigo será dispensada no caso de cobranças judiciais cujo valor seja inferior ao mínimo fixado por ato do Ministro de Estado da Fazenda.
}

A sistemática para a contagem da prescrição intercorrente prevista no artigo 40 da Lei de Execução Fiscal foi sedimentada no recente julgamento do Recurso Especial Repetitivo ${ }^{\circ}$ 1.340.553/RS, que fixou as Teses $n^{\circ} 566,567,568,569,570$ e 571 do STJ. (BRASIL, 2018)

O julgado perfilhou o entendimento de que o disposto no artigo 40 da Lei de Execução Fiscal inicia-se automaticamente a partir da intimação da Fazenda Pública acerca da não localização do devedor ou da ausência de bens a serem penhorados.

Assim, no primeiro momento em que constatada a não localização do executado ou a inexistência de bens penhoráveis no endereço fornecido, o ente público deverá ser intimado, a partir da qual inicia-se o prazo de um ano de suspensão do processo e automaticamente o 
quinquênio prescricional intercorrente, nos moldes da Súmula 314 do Superior Tribunal de Justiça. $^{11}$

No período de seis anos a partir de sua intimação (um ano de suspensão mais cinco anos de prescrição), o Fisco deverá ser eficiente no sentido de encontrar o executado ou bens passíveis de penhora, tendo em vista que, conforme decidido no julgado, somente "a efetiva constrição patrimonial ou a efetiva citação (ainda que por edital) são aptas a interromper o curso da prescrição intercorrente, não bastando para tal o mero peticionamento em juízo".

Ainda, as diligências requeridas pelo exequente deverão ser levadas em consideração além do período de seis anos, na ocorrência de uma eventual citação ou constrição após o prazo, hipótese na qual será considerada a interrupção da prescrição retroativamente na data do protocolo da petição que requereu a diligência frutífera.

Oportuno o registro de que o ente público, ao alegar nulidade pela falta de intimação no procedimento, deverá demonstrar o prejuízo que sofreu, bem como o magistrado, ao reconhecer a prescrição intercorrente, deverá fundamentar a decisão por meio da delimitação dos marcos legais que foram utilizados na contagem do prazo prescricional.

No procedimento estabelecido o magistrado deve declarar a suspensão do processo, fato, entretanto, que não afeta o início da contagem do período de suspensão e de prescrição a partir da intimação do ente público, para evitar a eternização das demandas e a insegurança jurídica.

Da análise do julgado, é possível verificar que a Corte Superior atrelou a ocorrência da prescrição intercorrente (prescrição processual) ao princípio da segurança jurídica, à razoável duração do processo e ao diálogo processual, com funções a serem exercidas pelo magistrado e pela Fazenda Pública.

De um lado, o magistrado como condutor do processo deverá suspendê-lo, bem como deferir as diligências requeridas e decretar a prescrição de maneira fundamentada, quando for o caso. De outro, a Fazenda Pública deverá ser efetiva no que tange à citação do executado no endereço correto e à localização de bens penhoráveis, sob pena de ter o seu crédito tributário declarado prescrito, vez que as diligências infrutíferas não são aptas a interromper a prescrição.

$\mathrm{O}$ procedimento também visa estabelecer um fim ao processo, de modo a trazer segurança jurídica aos litigantes e evitar a eternização de demandas que prejudiquem o

\footnotetext{
${ }^{11}$ Súmula 314 - Em execução fiscal, não localizados bens penhoráveis, suspende-se o processo por um ano, findo o qual se inicia o prazo da prescrição quinquenal intercorrente. (Súmula 314, PRIMEIRA SEÇÃO, julgado em 12/12/2005, DJ 08/02/2006 p. 258).
} 
contribuinte, conforme evidencia-se na fundamentação do acórdão: “Com efeito, o espírito da lei é o de que nenhuma execução fiscal já ajuizada poderá permanecer eternamente nos escaninhos do Poder Judiciário ou da Procuradoria encarregada da execução das respectivas dívidas fiscais".

Esse entendimento inclusive foi adotado através da Súmula $\mathrm{n}^{\circ} 150^{12}$ do Supremo Tribunal Federal o qual dispõe que "prescreve a execução no mesmo prazo de prescrição da ação", ou seja, no prazo anteriormente citado de cinco anos, nos termos do previsto no artigo 174 do CTN.

Nas palavras de Eduardo Sabbag:

\begin{abstract}
Evidencia-se, assim, no contexto atual, a ideia de que a Fazenda Pública, abandonando a execução fiscal, dará ensejo à prescrição intercorrente, em razão da paralisação superior a um quinquênio legal. Nesse passo, a prescrição intercorrente pressupõe a inércia do exequente. (SABBAG, 2013, p. 835).
\end{abstract}

Sendo assim, a prescrição intercorrente ocorrerá diante da inércia ou da ineficiência do ente público a partir da sua intimação acerca da não localização do devedor ou de bens do executado.

A Fazenda Pública deverá ser efetiva, no sentido de solicitar diligências para a citação do devedor ou para a localização de bens dentro do prazo de seis anos estabelecidos no julgamento repetitivo, para a não caracterização da prescrição intercorrente no caso concreto.

3.4 A subjetividade do enunciado da Súmula 106 do Superior Tribunal de Justiça e a aplicação subsidiária do Código de Processo Civil nas execuções fiscais.

A Súmula 106 do Superior Tribunal de Justiça dispõe que caso a demora na citação decorra do aparato judicial, não há que se falar em prescrição ou decadência: "Proposta a ação no prazo fixado para o seu exercício, a demora na citação, por motivos inerentes ao mecanismo da justiça, não justifica o acolhimento da arguição de prescrição ou decadência"13.

\footnotetext{
${ }^{12}$ Súmula 150 - Prescreve a execução no mesmo prazo de prescrição da ação. (Súmula da Jurisprudência Predominante do Supremo Tribunal Federal - Anexo ao Regimento Interno. Edição: Imprensa Nacional, 1964, p. 84.)

${ }^{13}$ Súmula 106 - Proposta a ação no prazo fixado para o seu exercício, a demora na citação, por motivos inerentes ao mecanismo da justiça, não justifica o acolhimento da arguição de prescrição ou decadência. (Súmula 106, CORTE ESPECIAL, julgado em 26/05/1994, DJ 03/06/1994 p. 13885).
} 
Por consequência, tal posicionamento restou sedimentado no julgamento do Recurso Especial $n^{\circ} 1102431 / R J$, de relatoria do Ministro Luiz Fux, julgado submetido ao rito dos recursos repetitivos. (BRASIL, 2009)

O julgado supracitado teve como fundamento a necessidade da estabilização das demandas através do instituto da prescrição, decorrente da inércia do credor, fato que não ocorre caso a culpa seja exclusiva do aparato judicial.

Nesse quesito, fundamental o destaque da subsidiariedade do Código de Processo Civil em relação à Lei de Execução Fiscal, demonstrado no RESP 1652984/PE' em que, nas hipóteses da aplicação da Súmula 106 do STJ, a interrupção da prescrição retroage à data da propositura da ação, em entendimento conjunto com o artigo $240^{14}, \S 1^{\circ}$ e $2^{\circ}$ do CPC, para que a Fazenda Pública não seja prejudicada.

Em que pese a leitura do enunciado sumular ser de certo modo simples, o caráter subjetivo da expressão "motivos inerentes ao mecanismo da justiça" pode gerar divergências de entendimento na aplicação de tal dispositivo.

Desse modo, é imprescindível a análise da jurisprudência relativa às execuções fiscais para obter-se uma conclusão acerca do assunto.

\section{A PRESCRIÇÃO DAS EXECUÇÕES FISCAIS E O MODELO COOPERATIVO PROCESSUAL NAS DECISÕES DO TRIBUNAL DE JUSTIÇA DO ESTADO DO PARANÁ}

Ante os desdobramentos do processo cooperativo no novo Código de Processo Civil e levando-se em conta as particularidades do instituto da prescrição tributária, surge uma indagação a ser respondida: na atuação do magistrado, quando poderá ser considerada a Súmula 106/STJ ou decretada a prescrição tributária nas execuções fiscais?

Para a obtenção da resposta, é de suma importância verificar o entendimento do Tribunal de Justiça do Estado do Paraná, o qual utilizamos como parâmetro de análise nesse estudo, quanto à aplicabilidade do modelo cooperativo processual no curso das execuções fiscais.

\footnotetext{
${ }^{14}$ Art. 240. A citação válida, ainda quando ordenada por juízo incompetente, induz litispendência, torna litigiosa a coisa e constitui em mora o devedor, ressalvado o disposto nos arts. 397 e 398 da Lei ${ }^{\circ} 10.406$, de 10 de janeiro de 2002 (Código Civil). § $1^{\circ}$ A interrupção da prescrição, operada pelo despacho que ordena a citação, ainda que proferido por juízo incompetente, retroagirá à data de propositura da ação. § $2^{\circ}$ Incumbe ao autor adotar, no prazo de 10 (dez) dias, as providências necessárias para viabilizar a citação, sob pena de não se aplicar o disposto no $\S 1^{\circ}$.
} 
Em verificação aos julgados da $1^{\text {a }}$ Câmara Cível ${ }^{15}$, denota-se que o princípio do impulso oficial poderá ser relativizado. Em que pese sua natureza inquisitiva e o dever do magistrado de ser o condutor do processo, cabe também ao exequente o acompanhamento do trâmite processual, em conformidade com o princípio da cooperação entre os sujeitos processuais e com o da segurança jurídica.

Em diversas e recentes oportunidades, a $2^{\mathrm{a}}$ Câmara Cível tem repisado este entendimento, devendo o princípio do impulso oficial ser sopesado com os princípios da inércia e do dispositivo, para um andamento efetivo do processo visando a tutela do direito pleiteado(BRASIL,2017).

Por fim, a Terceira Câmara Cível ${ }^{16}$ adota o mesmo posicionamento, consolidando um entendimento unânime do Tribunal de Justiça do Paraná, apesar das variáveis existentes no histórico processual de cada caso concreto.

Note-se que, ao relativizar o princípio do impulso oficial e ponderá-lo com o princípio dispositivo, o que está sendo efetivamente feito é uma análise do modelo cooperativo de processo no curso das execuções fiscais, através da atuação do magistrado e da parte (Fazenda Pública).

O recente Recurso Especial Repetitivo no 1.340.553/RS citado anteriormente também corrobora este entendimento, pois atribuiu ao magistrado e à Fazenda Pública condutas a serem observadas no andamento processual para a sistemática da contagem do prazo da prescrição intercorrente.

A aplicação conjunta da jurisprudência com a leitura do Enunciado da Súmula 106 do Superior Tribunal de Justiça permite uma melhor elucidação sobre o tema, apta a afastar o caráter subjetivo sumular.

No caso de o ente público não ter sido efetivamente diligente visando a satisfação do direito pleiteado, será possível o reconhecimento da prescrição após o transcurso do quinquênio prescricional.

Por outro lado, aplica-se a Súmula 106 diante da falha no impulso oficial, seja pela demora na realização dos atos judiciais ou pela falta de intimação da Fazenda Pública.

Outrossim, cabe ressaltar ainda sobre a necessidade de o exequente ser minimamente diligente em busca da satisfação da obrigação tributária, de modo a não abandonar a execução fiscal em seu curso ${ }^{17}$.

\footnotetext{
${ }^{15} \mathrm{TJ} / \mathrm{PR}$ - AC 1544862-9, $1^{\text {a }}$ C. Cível, Rel. Des. Rubens Oliveira Fontoura, 28.06.16. TJ/PR - AC 1655896-4, $1^{a}$ C. Cível, Rel. Des. Salvatore Antonio Astuti, 30.05.17.

${ }^{16}$ TJ/PR - AC 1554541-8, $3^{\text {a }}$ C. Cível, Rel. Des. Sérgio Roberto Rolanski, 07.02.17 TJ/PR - AC 1578478-2, $3^{\mathrm{a}}$

C. Cível, Rel. Des. Marcos S. Galliano Daros, 07.02.17.
} 


\section{CONCLUSÃO}

Pelo exposto, é de se concluir que a perda da pretensão executiva, com a ocorrência do instituto da prescrição tributária, está associada ao processo cooperativo: a atuação do magistrado e a manifestação da Fazenda Pública no decorrer do processo.

Nesse contexto, levando-se em consideração a dialeticidade do processo, a extinção dos créditos tributários pela prescrição poderá ocorrer quando houver falha no diálogo processual.

Caso não ocorra o devido impulso oficial, seja pela falta de intimação da parte, seja pela demora dos atos judiciais, não há que se falar em perda da pretensão executiva, aplicando-se a Súmula 106 do STJ, conforme julgado submetido ao rito dos recursos repetitivos citado no item 3.4 do presente artigo.

Por outro lado, caso a Fazenda Pública não seja efetiva requerendo diligências a fim de citar o executado ou, após a citação, não tenha êxito na busca de bens visando o adimplemento da obrigação, tendo transcorrido o lapso prescricional, o magistrado deverá extinguir o feito em decorrência da prescrição tributária, nos termos do artigo 174 do Código Tributário Nacional ou do artigo 40 da Lei de Execuções Fiscais com a sistemática definida por ocasião do julgamento do Recurso Especial Repetitivo $n^{\circ} 1.340 .553 / \mathrm{RS}$.

Desse modo, a aplicabilidade conjunta do modelo cooperativo do Código de Processo Civil com a atuação dos sujeitos processuais nas execuções fiscais permite o reconhecimento das hipóteses da prescrição tributária, visando assim a primazia da aplicação dos princípios constitucionais da razoável duração do processo e da segurança jurídica, evitando, dessa forma, a eternização das demandas judiciais.

\section{REFERÊNCIAS}

${ }^{17}$ TJ/PR - AC 1726864-9, $3^{\text {a } ~ C . ~ C i ́ v e l, ~ R e l . ~ D e s . ~ E d u a r d o ~ S a r r a ̃ o, ~ 19.09 .17 . ~ T J / P R ~-~ A C ~ 1734093-5, ~} 3^{\text {a }}$ C. Cível, Rel. Des. José Laurindo de Souza Netto, 24.10.17. 
ARAÚJO, Fábio Caldas de. Curso de Processo Civil: tomo 1 - parte geral. $1^{\text {a }}$ edição. São Paulo: Editora Malheiros, 2016.

ARENHART, Sérgio Cruz; MARINONI, Luiz Guilherme; MITIDIERO, Daniel. Novo curso de processo civil: teoria do processo civil. Volume $1.3^{\text {a }}$ edição. rev., atual. e ampl. São Paulo: Editora Revista dos Tribunais, 2017.

BARACAT, E.M.; PESCAROLO, C ; BARBOSA, S. P. M. . Regulação - agências reguladoras independentes - forma de intervenção indireta do Estado na atividade econômica. In: Gustavo Afonso Martins; Marina Zagonel Xavier da Silva; Daniella Lopes de Lima; Jean Colbert Dias; Roberlei Aldo Queiroz; Leandro Souza Rosa; Mauro de Paulo Branco; Soraia Paulino Marchi Barbosa; Rogério C. Dantas Cachichi. (Org.). Diálogos (Im)pertinentes: Desafios para a concreção constitucional. 1ed.Curitiba: Instituto Memória, 2018, v. 6, p. 27 49.

; MACHADO, C. D; GUNTHER, L. E. A análise econômica da terceirização. In: Viviane Coêlho de Séllos-Knoerr; Luciana Aboim Machado; Irene Maria Portela. (Org.). Diálogos (Im)pertinentes: Desafios para a concreção constitucional. 1ed.Curitiba: Instituto Memória, 2018, v. 3, p. 31-49.

BRASIL. Lei $\mathrm{n}^{\circ}$ 5.172, de 25 de outubro de 1966. Código Tributário Nacional. Diário Oficial da União, Brasília, DF, 31 de outubro de 1966. Disponível em:

<http://www.planalto.gov.br/ccivil_03/leis/L5172Compilado.htm>. Acesso em: 20 nov. 2019.

Lei $n^{\circ}$ 6.830, de 22 de setembro de 1980. Lei de Execução Fiscal. Diário Oficial da União, Brasília, DF, 24 de setembro de 1980. Disponível em:

<http://www.planalto.gov.br/ccivil_03/leis/L6830.htm>. Acesso em: 20 nov. 2019.

Lei $\mathrm{n}^{\circ}$ 11.051, de 29 de dezembro de 2004. Diário Oficial da União, Brasília, DF, 30 de dezembro de 2004. Disponível em: <http://www.planalto.gov.br/ccivil_03/_ato20042006/2004/lei/L11051.htm>. Acesso em: 20 nov. 2019.

Lei $\mathrm{n}^{\circ}$ 13.105, de 16 de março de 2015. Código de Processo Civil. Diário Oficial da União, Brasília, DF, 17 de março de 2015. Disponível em: <http://www.planalto.gov.br/ccivil_03/_ato2015-2018/2015/lei/113105.htm>. Acesso em: 20 nov. 2019.

Lei Complementar $n^{\circ} 118$, de 09 de fevereiro de 2005. Diário Oficial da União, Brasília, DF, 09 de fevereiro de 2005. Disponível em: <http://www.planalto.gov.br/ccivil_03/Leis/LCP/Lcp118.htm>. Acesso em: 20 nov. 2017.

Supremo Tribunal Federal. Súmula 150 - Prescreve a execução no mesmo prazo de prescrição da ação. (Súmula da Jurisprudência Predominante do Supremo Tribunal Federal - Anexo ao Regimento Interno. Edição: Imprensa Nacional, 1964, p. 84.

Superior Tribunal Federal. Súmula 106. Proposta a ação no prazo fixado para o seu exercício, a demora na citação, por motivos inerentes ao mecanismo da justiça, não 
justifica o acolhimento da arguição de prescrição ou decadência. CORTE ESPECIAL, julgado em 26/05/1994, DJ 03/06/1994 p. 13885.

. Superior Tribunal de Justiça. REsp 1102431/RJ. Processual civil. Tributário. Recurso especial representativo de controvérsia. Art. 543-c, do cpc. Execução fiscal. Prescrição intercorrente. Paralisação do processo por culpa do poder judiciário. Súmula 106 do stj. Reexame de matéria fático-probatória. SÚMULA 07/STJ.Primeira Seção, Rel. Min. Luiz Fux, 09.12.2009. Disponível em: https://stj.jusbrasil.com.br/jurisprudencia/640705998/recurso-especial-resp-1772529-al-20180263977-8? ref=serp>. Acesso em: 26 mar.2019.

Superior Tribunal de Justiça. Resp 999.901/RS. Processual civil.recurso especial representativo de controvérsia.art.543-c, do cpc. Execução fiscal.prescrição. Citação por edital.interrupção. Precedentes. Disponível em: <https://stj.jusbrasil.com.br/jurisprudencia/4237747/recurso-especial-resp-999901-rs-20070251650-1/inteiro-teor-12210199>. Acesso em: 24 nov. 2018.

. Superior Tribunal de Justiça. REsp 1320825/RJ. Tributário. Recurso especial repetitivo. Ipva. Decadência. Lançamento de ofício. Regularidade.prescrição. Parâmetros. Primeira Seção, Rel. Min. Gurgel de Faria, 10.08.2016. Disponível em: < https://www.migalhas.com.br/arquivos/2016/8/art20160830-03.pdf>. Acesso em: 23 nov. 2018.

Superior Tribunal de Justiça. REsp 1340553/RS. Arts.1,036 e seguintes do cpc. Processual civil.tributário. sistemática para contagem da prescrição intercorrente. Primeira Seção, Rel. Min. Mauro Campbell Marques, 12.09.2018. Disponível em: < https://stj.jusbrasil.com.br/jurisprudencia/638023415/recurso-especial-resp-1340553-rs-20120169193-3/inteiro-teor-638023436>. Acesso em: 26 nov. 2018.

Supremo Tribunal de Justiça. Súmula 314. Em execução fiscal, não localizados bens penhoráveis, suspende-se o processo por um ano, findo o qual se inicia o prazo da prescrição quinquenal intercorrente. PRIMEIRA SEÇÃO, julgado em 12/12/2005, DJ 08/02/2006 p. 258.

Superior Tribunal de Justiça. REsp 1652984/PE. Processual civil. Tributário. Execução fiscal. Inércia da fazenda nacional. Prescrição intercorrente. Aplicação da súmula 106/stj. Devolução de aviso de recebimento. Segunda Turma, Rel. Min. Herman Benjamin, 04.04.2017. Disponível em: < https://www.portaljustica.com.br/acordao/2024238>. Acesso em: 27 nov. 2018.

Tribunal de Justiça do Estado do Paraná. AC 1712713-8. Tributário. Apelação cível. Execução fiscal. Extinção. Sentença que condenou o ente municipal ao pagamento de custas processuais. Afastamento da taxa judiciária nesta decisão. Recurso parcialmente conhecido (artigo 1010, iii, do cpc) e na parte conhecida, parcialmente provido. $2^{\mathrm{a}}$ c. Cível, rel. Des. Silvio dias, 03.10.2017. Disponível em: < https://portal.tjpr.jus.br/jurisprudencia/j/4100000008258511/Ac\%C3\%B3rd\%C3\%A3o$0011010-$

85.2004.8.16.0129;jsessionid=ad0e1cfeb0f0fcb803b31b90dcaa\#integra_4100000008258511> . Acesso em: 23 nov. 2018. 
Tribunal de Justiça do Estado do Paraná. AC

1726347-3. Decisão monocrática. Apelação cível. Execução fiscal.Extinção. Reconhecimento da prescrição intercorrente. Condenação do exequente em custas processuais. Recurso que se refere ao reconhecimento da ilegitimidade passiva do executado na análise de exceção de pré executividade. Ofensa ao princípio da dialeticidade. Argumentos do apelante que não rebatem os fundamentos da sentença. Art. 932, iii, cpc.não conhecimento do recurso. $2^{\text {a }}$ C. Cível, Rel. Des. Antônio Renato Strapasson, dje. 31.10.2017. Disponível em: < https://portal.tjpr.jus.br/jurisprudencia/j/4100000011346082/Decis\%C3\%A3o\%20monocr\%C 3\%A1tica-0004399-37.2009.8.16.0034;jsessionid=51261c5e1a244e15581700f9e770>.

Acesso em: 23 nov. 2018.

CALCINI,F.P; CRUZ,J.C.de C. Responsabilidade tributária sob enfoque da súmula 435 do STJ. Revista Jurídica - UNICURITIBA. Curitiba, 2019, n.56, v.3, p.326-353.Disponível em: < http://revista.unicuritiba.edu.br/index.php/RevJur/article/view/3580/371371971>. Acesso em: 29 out. 2019.

CARRAZZA, Roque Antônio. Operações interestaduais com contribuintes, não-contribuintes e consumidores finais e as alíquotas aplicadas. Revista de Direito Tributário (São Paulo), v. 1, p. 167-172, 2016.

O conceito de mercadoria para fins de tributação por meio de ICMS. Novas Tendências do ST. Revista de Direito Tributário (São Paulo), v. 1, p. 23-27, 2015.

Curso de Direito Constitucional Tributário. 32. ed. v.1.São Paulo / SP: Malheiros Editores, 2019.

ICMS. 17a . ed. v. 1. São Paulo / SP: Malheiros Editores, 2015.

CORREIA, T.F.; SANTANA, H.L.de S.; BORGES, A. de M. A mudança de paradigma do direito tributário quanto ao sigilo bancário. Revista Jurídica - UNICURITIBA. Curitiba, 2016, n.44, v.3, p.568-596.Disponivel em: http://revista.unicuritiba.edu.br/index.php/RevJur/article/view/1880/1250>. Acesso em: 29 out.2019.

DIDIER JÚNIOR, Fredie. Curso de Direito Processual Civil: introdução ao direito processual civil, parte geral e processo de conhecimento. $19^{a}$ edição. Salvador: Editora JusPodivm, 2017.

DONIZETTI, Elpídio; QUINTELLA, Felipe. Curso Didático de Direito Civil. $6^{\text {a }}$ edição. rev. e atual. São Paulo: Editora Atlas, 2017.

GRUPENMACHER, Betina Treiger; RODRIGUES, M. S. Z. A tributação Extrafiscal de Indução através dos incentivos fiscais -Análise do Incentivo Fiscal incidente sobre a contribuição do seguro de Acidentes do Trabalho. Revista Abradt Forum de Direito Tributário, v. 1, p. 57-75, 2018 
; ÁVILA, H. B; CARVAlHO, P. B; DERZI, M. A. M; MACHADO, H. B. Os Processos Judiciais e Administrativos Tributários e o Incidente de Desconsideração da Personalidade Jurídica do Novo Código de Processo Civil. Revista de Estudos Tributários (Porto Alegre), v. 1, p. 130-148, 2016.

Execução Fiscal - Penhora 'On Line' e a Lei Complementar 118/2005. Revista de Direito Tributário, São Paulo, v. 1, n.93, p. 5-318, 2006.

; MOREIRA, Egon Bockman; KANAYAMA, Rodrigo Luiz; AGOTTANI, D. Z. Precatórios. O seu novo regime jurídico. 1. ed. v.1. São Paulo: Revista dos Tribunais, 2017.

HABLE, José. A Extinção do Crédito Tributário por Decurso de Prazo. Decadência e Prescrição Tributárias. $4^{a}$ edição. São Paulo: Editora Método, 2014.

MACEI, D. N.; MEIRA JUNIOR, J. J. O convênio administrativo como instrumento jurídico para o fomento no âmbito do ICMS. ANIMA: Revista Eletrônica do Curso de Direito da OPET, v. Ano X, p. 1-29, 2018.

; MEIRA JUNIOR, J. J. Análise dos Princípios Constitucionais da Ordem Econômica e sua Influência no Direito Brasileiro. ANIMA: Revista Eletrônica do Curso de Direito da OPET, v. 16, p. 130-154, 2017.

Ato Cooperativo \& tributação. $2^{\text {a }}$ ed. rev. e atual. Curitiba: Juruá, 2014.

Direito Tributário. 1. ed. vol. 1. Florianópolis: CONPEDI, 2014.

MARINONI, Luiz Guilherme; MITIDIERO, Daniel. Código de Processo Civil: comentado artigo por artigo. $6^{a}$ edição. rev. e atual. São Paulo: Editora Revista dos Tribunais, 2014.

MARINONI, Luiz Guilherme; MITIDIERO, Daniel. Direitos Fundamentais Processuais. In: SARLET, Ingo Wolfgang. Curso de Direito Constitucional. $2^{a}$ edição. São Paulo: Editora Revista dos Tribunais, 2013.

NEVES, Daniel Amorim Assumpção. Manual de Direito Processual Civil - Volume único. $9^{a}$ edição. Salvador: Editora JusPodivm, 2017.

PELUSO, Cezar, coordenador. Código Civil comentado: doutrina e jurisprudência. $7^{\mathrm{a}}$ edição. rev. e atual. Barueri, São Paulo: Editora Manole, 2013.

POZZETTI, V.C.; LIMA, H.C.P de. Planejamento sucessório: uma abordagem tributária e empresarial. Revista Jurídica - UNICURITIBA. Curitiba, 2018, n.52, v.3, p.324-352. Disponível em: < http://revista.unicuritiba.edu.br/index.php/RevJur/article/view/3061/371371595>. Acesso em: 29 out. 2019.

SABBAG, Eduardo. Manual de Direito Tributário. 5a edição. São Paulo: Saraiva, 2013.

SOUZA NETTO, José Laurindo de. A Confluência dos Modelos Dispositivos e Inquisitivo do Processo Civil Operada pelo Princípio da Cooperação. In: NASCIMENTO, Grasiele Augusta Ferreira; RAMOS, Paulo Roberto Barbosa; MARTINS, Argemiro Cardoso Moreira, coordenadores. Constituição e Democracia II. $1^{\text {a }}$ ed. Florianópolis: Conpedi, 2016, v. 1, p. 
402-419. XXV ENCONTRO NACIONAL DO CONPEDI - BRASÍLIA/DF. Disponível em <https://www.conpedi.org.br/publicacoes/y0ii48h0/509my5cz/jQArPjlHT61BmF15.pdf>. Acesso em: 20 nov. 2017.

THEODORO JÚNIOR, Humberto. Curso de Direito Processual Civil - Teoria geral do direito processual civil e processo de conhecimento. $53^{\text {a }}$ Edição. Volume 1. Rio de Janeiro: Editora Forense, 2012.

WAMBIER, Luiz Rodrigues; ALMEIDA, Flávio Renato Correia de; TALAMINI, Eduardo. Curso Avançado de Processo Civil, volume 1: teoria geral do processo de conhecimento. $7^{\mathrm{a}}$ edição. rev. e atual. São Paulo: Editora Revista dos Tribunais, 2005.

WAMBIER, Teresa Arruda Alvim; CONCEIÇÃO, Maria Lúcia Lins; RIBEIRO, Leonardo Ferres da Silva; MELLO, Rogerio Licastro Torres de. Primeiros Comentários ao Novo Código de Processo Civil Artigo por Artigo. $1^{\mathrm{a}}$ edição. São Paulo: Editora Revista dos Tribunais, 2015. 